\title{
DYNAMIC REGULATION OF NATURAL SCENIC AREA SYSTEM FROM THE PERSPECTIVE OF ECOLOGICAL CIVILIZATION
}

\author{
Yuyan $\mathrm{LUO}^{1,2, *}$, Lu YIN ${ }^{1}$, Yong QIN ${ }^{1}$ and Zhong WANG ${ }^{1}$
}

${ }^{1}$ College of Management Science, Chengdu University of Technology, Chengdu 610059, China.

${ }^{2}$ Post-doctorate R \& D Base of Management Science and Engineering, Chengdu University of Technology, Chengdu 610059, China.

*Autor de correspondencia: luoyuyan13@mail.cdut.edu.cn

(Received May 2018; accepted July 2018)

Key words: ecological civilization, system dynamics, natural scenic area system, regulation and analysis

\begin{abstract}
Ecological civilization is an organic unity of theory and practice. The ecological civilization of natural scenic areas has received extensive attention from scholars at home and abroad in recent years. This paper explores the connotation of ecological civilization of natural scenic area system and constructs a natural scenic area system model based on system dynamics. In addition, this paper takes Jiuzhai Valley as research object to regulate and analyze the key factors that may affect ecological civilization construction in scenic areas, explores scenic area development trend under different strategies, and provides a basis for the promotion of ecological civilization construction in natural scenic areas.
\end{abstract}

Palabras clave: civilización ecológica, dinámica de sistemas, área escénica natural, regulación y análisis

\section{RESUMEN}

La civilización ecológica es una unidad orgánica en la teoría y la práctica. Las áreas escénicas naturales han recibido, en años recientes, una gran atención por los académicos, tanto en China como en el exterior como parte de la civilización ecológica. Este trabajo explora las connotaciones de los sistemas de áreas naturales escénicas en la civilización ecológica y construye un modelo de sistema de área natural escénica con base en la dinámica de sistemas. Adicionalmente, el trabajo toma como objeto de estudio el Valle Jiuzhai para regular y analizar los factores clave que puedan afectar la construcción de la civilización ecológica en áreas escénicas, explora las tendencias de desarrollo de áreas escénicas bajo diferentes estrategias y proporciona una base para la promoción de la civilización ecológica e áreas escénicas naturales. 


\section{INTRODUCTION}

Ecological civilization construction is the ecological manifestation of a higher-level social civilization and an inevitable choice for achieving ecological security and economic and social sustainable development (Zhang et al., 2016; Zhao and Li, 2018). At present, the global ecological civilization construction has entered a new stage of green development, and gradually becomes an important part of China's economic and social development (Yu et al., 2017; Zhu and Gao, 2014; Liu et al., 2013). The construction of ecological civilization in natural scenic areas is an important manifestation of the concept of ecological civilization, and also a strategic choice to coordinate harmonious development between man and nature and achieve sustainable development of tourism industry (Wang, 2017). More importantly, it is an essential way to solve the resource and environment problems emerging from the excessively rapid development of tourism industry.

There are relatively few researches on the relations between ecological civilization construction and natural scenic area system (NSAS) at home and abroad. Most foreign scholars focus on the issue of ecotourism, economic value evaluation of ecotourism, ecotourism planning, and ecotourism development and management (Kamali et al., 2017; De Leon and Kim, 2017; Villanueva-Alvaro et al., 2017). Domestic scholars choose almost the same research direction as foreign scholars do. In 2007, the Communist Party of China clearly put forward the concept of "ecological civilization" and rose the construction of ecological civilization to the state will, emphasizing that ecological civilization construction is specific application and an important practice of international sustainable science in China, and a necessary requirement to realize sustainable development of tourism in China (Qin and $\mathrm{Ju}, 2017)$. Under the call of the country, in view of basic concepts, theories, and foundations of ecological civilization, many scholars associated ecological civilization with tourism and studied on the coordinated state of ecological civilization and tourism, pointing out that ecotourism, cultural tourism and rural tourism were three main development forms of ecological civilization construction (Yang, 2016; Guo et al., 2017; Xu et al., 2017). In addition, scholars clarified that under the guidance of ecological civilization concept, the attempt to combine these three basic tourism forms would create more advanced tourism forms, such as combining rural tourism and ecological tourism to create a new model of tourism development form: rural ecotourism (Tang et al., 2017).

Thus, this paper adopts system dynamics (SD) theory to construct a NSAS system flow diagram based upon tracking study on Jiuzhai Vally Natural Scenic Area from the perspective of ecological civilization. Through literature research, like questionnaire survey, expert consultation and induction analysis, etc., this paper collects relevant data information, conducts reasonable parameter estimation on hard-to-quantified variables of necessary researches, makes the simulation system approximate to the real system, then regulates and analyzes key factors that may affect the construction of ecological civilization in scenic areas after testing on the simulation system passes, so as to provide basis for promotion of ecological civilization construction and sustainable development in natural scenic areas.

\section{CONNOTATION OF NSAS ECOLOGICAL CIVILIZATION AND SD MODEL}

\section{Connotation of NSAS ecological civilization}

Ecological civilization is symbolized by sustainable development with the goal of establishing an ecologically civilized society, and committed to improving the ecological environment on the criterion of people-oriented, all-round, coordinated and sustainable scientific outlook on development, moral outlook that does not infringe on the rights to survival and development of future generations, and values of a harmonious relationship between man and nature (Chen et al., 2017). The construction of ecological civilization is a rather complex issue that needs to take many factors into consideration, but the most important thing is to grasp the definition of coordinated development of ecological civilization (Chai et al., 2017).

Natural scenic areas rely on effective protection of natural and cultural heritage resources and long-term improvement of land and water features and ecological environment. The advocation of ecological civilization construction when constructing and developing natural scenic areas owns a unique advantage, then becomes urgent and important (Mao, 2016). Ecological civilization construction is the cornerstone of tourism development in natural scenic areas, and will play an important role in the long-term development of natural scenic areas in the future. 
The development of low-carbon economy is the foundation of ecological civilization construction (Wu et al., 2017). It can be seen from the connotation of low-carbon economy that decarbonated and sustainable construction and development of natural scenic areas has a certain impact on the growth of tourists' quantity. Combined with China's reality, the implementation of decarbonated and sustainable development in natural scenic areas relies on the support from tourism revenue. Therefore, in the process of low-carbon development, the correct attitude and management towards the relationship between tourism economic growth and ecological civilization construction is the key to keep the sustainable development trend of scenic areas. Ecological civilization requires natural scenic areas not only to achieve economic growth, but also to meet the "triple bottom lines" to achieve a balanced development of economic, social and ecological benefits in natural scenic areas.

\section{NSAS boundary and structure}

The construction of natural scenic areas meeting the development demands of ecological civilization is a concrete reflection of sustainable and protective development. Meanwhile, the ecological civilization perspective also provides a new method for the coordinated development of its multiple subsystems. Based on the refinement of NSAS structure under the perspective of ecological civilization and the selfdevelopment of natural scenic areas, this paper proposes a composite system benefit consisting of five aspects: economic operation, social development, ecological representation, decarbonated control, and constructive guarantee. The five subsystems relate to, impact and restrict each other. The conceptual model is as follows:

$\operatorname{Max}(S)=f\left(x_{1}, x_{2}, x_{3}, x_{4}, x_{5}\right)$

Where, $S$ is NSAS, $x_{1}$ represents economic operation subsystem (EOS), $x_{2}$ is social development subsystem (SDS), $x_{3}$ shows environmental representation subsystem (ERS), $x_{4}$ indicates decarbonated control subsystem (DCS), and $x_{5}$ is constructive guarantee subsystem (CGS).

EOS refers to tourism economic benefits of natural scenic areas, which is reflected in the increase of tourists' quantity, reduction of operation costs and pursuit for low-cost, high-yield growth methods, so as to lay a material foundation for ecological civilization development of the system; SDS refers to social benefits of natural scenic areas, which mainly focuses on the aboriginal people's living standards, education, and employment during the normal operation of the system. The development of SDS plays a decisive role in the harmonious coexistence of man and scenery. ERS refers to the ecological benefits of natural scenic areas and provides closely related elements for ecological civilization construction in scenic areas, involving natural scenery, waterscapes, forest vegetation, biodiversity levels, air quality, surface water quality, etc.; DCS reflects the top priority of low-carbon development during the development of NSAS, including disposal and control on garbage, sewage discharge, carbon emissions, investment in environmental protection, etc.; CGS is the foundation of the benefits of natural scenic areas. It provides management and technical support and services for tourist reception, infrastructure construction, ecological protection, residents' lives, and carbon emissions control.

\section{Composite SD model of natural scenic areas (1) NSAS conceptual model}

On the basis of boundary division of NSAS and numerous literatures, the conceptual model of five subsystems including economic operation, ecological representation, social development, decarbonated control, and constructive guarantee is determined as follows:

$F\left(\mathrm{X}_{i}\right)=f\left(x_{i 1}, x_{i 2}, x_{i 3}, \cdots, x_{i n}\right)$

Where, the value of $i$ ranges from 1 to 5, representing the five subsystems of EOS, SDS, ERS, DCS, and CGS respectively; $x_{\text {in }}$ indicates variables of $i$ subsystem. Where, $x_{11}$ is scenic benefits, $x_{12}$ is construction in process, $x_{13}$ shows capacity of tourist reception, etc.; $x_{21}$ is air quality level, $x_{22}$ is tourists' quantity, $x_{23}$ refers to carbon content, etc.; $x_{31}$ is resident living standard, $x_{32}$ is service awareness, $x_{33}$ represents tourist satisfaction, etc.; $x_{41}$ is garbage's quantity, $x_{42}$ is garbage handling capacity, $x_{43}$ is pollution handling costs, etc.; $x_{51}$ is infrastructure investment, $x_{52}$ is construction under process, $x_{53}$ is capacity of tourist reception, etc.

\section{(2) NSAS flow diagram and equation}

SD flow diagram needs to be established based on the analysis of system feedback and relations between variables. NSAS flow diagram (Fig. 1) is based on the system structure and causality. SD equations are compiled to reveal the quantitative relations through the combination of the logic relationship between 


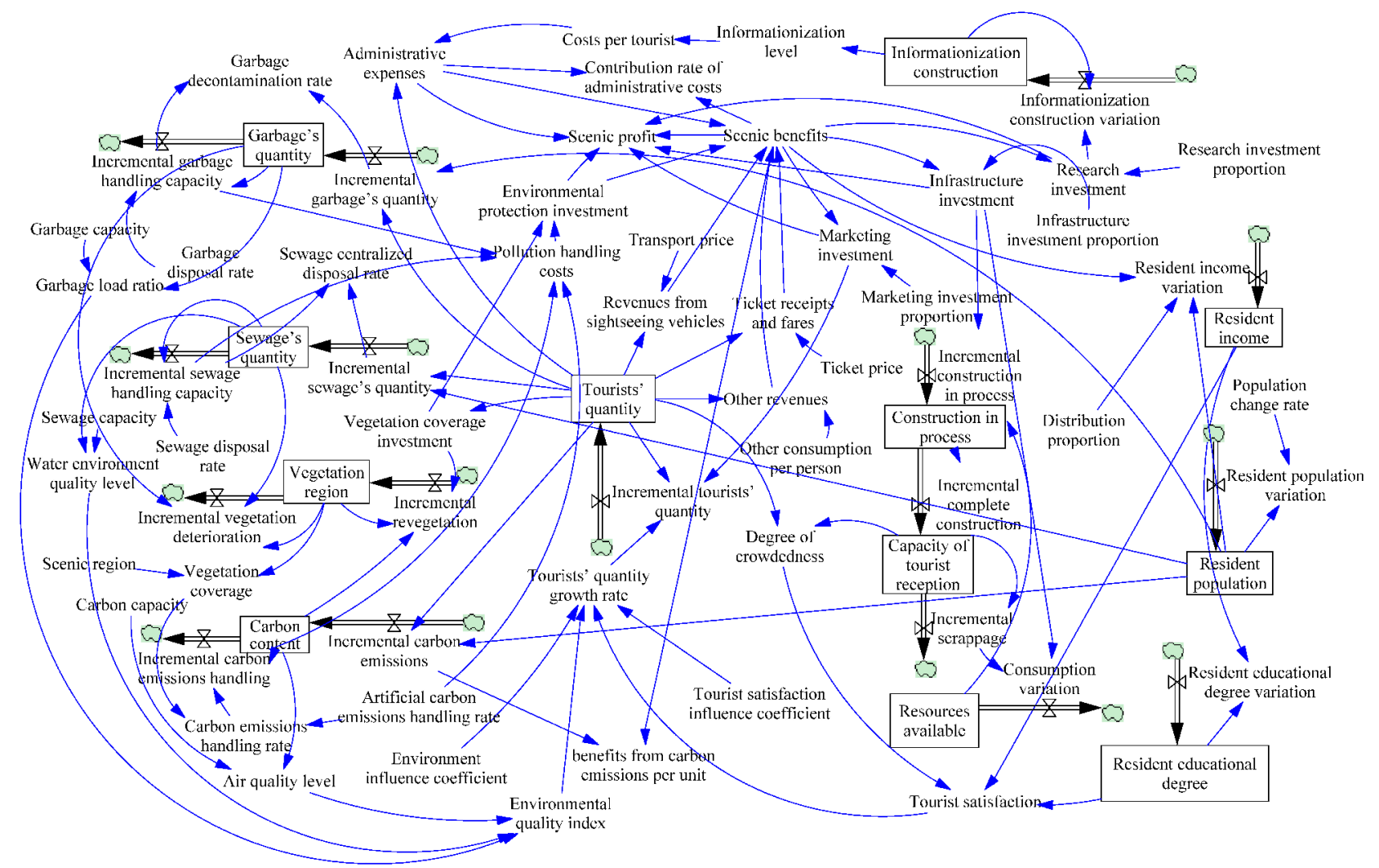

Fig. 1. NSAS flow diagram

variables and system construction (Luo et al., 2014). For example, in EOS, Tourists' quantity. $K=$ Tourists' quantity.J + Tourists' quantity variation.JK; Tourists' quantity variation. $K L=$ Tourists' quantity change rate. $K L \times$ Tourists' quantity. $K=$ Tourists , quantity growth rate. $K L \times$ Tourists' quantity. $K$; Tourists' quantity growth rate. $K=$ Environment influence coefficient. $K \times$ Environmental quality index $K+$ Tourist satisfaction influence coefficient. $K \times$ Tourist satisfaction.K; Scenic benefits.K = Ticket receipts and fares. $K+$ Revenues from sightseeing vehicles. $K+$ Other revenues. $K$ - Administrative expenses. $K$-Environmental protection investment.K; Contribution rate of administrative costs. $K=A d m i n-$ istrative expenses.K/Scenic benefits.K.

\section{EMPIRICAL ANALYSIS}

\section{Overview of survey region}

Jiuzhai Valley Natural Scenic Area enjoys high reputations of World Heritage Site, World Biosphere Reserve, and "Green Global 21" Sustainable De- velopment Tourism Protection Area. It is praised as "fairyland on earth" for orientals and "fairy tale world" for Westerners. Jiuzhai Valley is a national natural reserve with an area of 643 square kilometers and a total area of 720 square kilometers for tourist attractions. It was listed in the World Natural Heritage List in 1992. In 1997, it was included in the World Man and Biosphere Reserve; in 2000 it was named the first batch of 4A-level scenic spots in China; in February 2001, it won several reputations of "Green Globe" Certificate, National Outstanding Scenic Area, and Top of Three High Quality Tourism Products in Sichuan, etc.. Since 21st century, Jiuzhai Valley has been devoting itself to informationization, environmental and ecological protection while developing economy, which has laid a foundation for the unfold of an ecological civilization era of the scenic area.

\section{Parameter estimation and model checking (1) Parameter estimation}

The SD model of Jiuzhai Valley mainly includes parameters such as tourists' quantity, ecological 


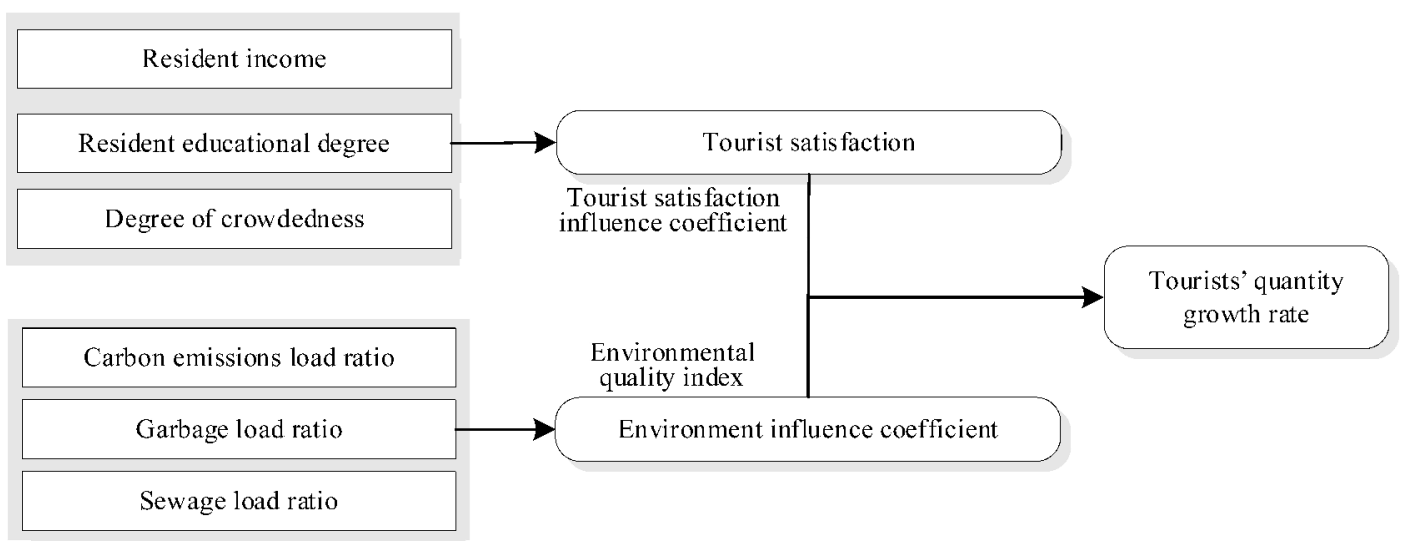

Fig. 2. Factor structure of tourist growth rate

environment, and residents' income. The parameters are mainly obtained through mathematical model method based on the data and information from Jiuzhai Valley Management Bureau. For example, the factor structure that affects the growth rate of tourists is shown in Fig. 2:

Tourist satisfaction comprehensively measures tourists' experience of management and service of scenic areas during the tour. The main factors influencing tourist satisfaction index are degree of crowdedness and service quality, while service quality is measured by variables such as income and educational degree of the staff (residents in the scenic area). Therefore, this paper proposes that tourist satisfaction is mainly examined from its relationship with degree of crowdedness, residents' income and educational degree.
Environmental quality index is used to measure NSAS's ecological civilization degree, which is mainly embodied by carbon emissions, garbage's quantity, and sewage discharge in Jiuzhai Valley. It can be measured by carbon emissions load ratio, garbage load ratio, and sewage load ratio.

Taking tourist satisfaction and environmental quality index as independent variables, and tourist growth rate as dependent variable, the regression model has statistical significance when the significant levels of parameter R2, F value and T value meet all requirement through regression analysis by SPSS software. Therefore, satisfaction impact coefficient and environmental impact coefficient can be obtained. At the same time, other parameters are obtained through field research and review of literatures, as Table I shows.

TABLE I. NSAS SYSTEM SIMULATION MODEL PARAMETER

\begin{tabular}{lcll}
\hline Parameters & Value & Units & Source \\
\hline Environment influence coefficient & 0.092 & Dimensionless & Data analysis \\
Tourist satisfaction influence coefficient & 1.083 & Dimensionless & Data analysis \\
Average consumption per tourist & 290 & Yuan & Field research \\
Distribution proportion & $5 \%$ & Dimensionless & Field research and review of literatures \\
Research investment proportion & $3 \%$ & Dimensionless & Review of literatures \\
Marketing investment proportion & $10 \%$ & Dimensionless & Review of literatures \\
Infrastructure investment proportion & $15 \%$ & Dimensionless & Field research and review of literatures \\
Garbage emissions per capita & 1.112 & Kilogram & Review of literatures \\
Sewage discharge per capita & 0.100 & Cubic meter & Review of literatures \\
Carbon emissions per capita & 0.005 & Kilogram & Field research and review of literatures \\
Garbage disposal rate & $97 \%$ & Dimensionless & Field research and review of literatures \\
Sewage disposal rate & $99 \%$ & Dimensionless & Field research and review of literatures \\
Artificial carbon emissions handling rate & $8 \%$ & Dimensionless & Field research \\
\hline
\end{tabular}

Note: Artificial carbon emissions handling rate refers to the ratio of carbon emissions that are reduced by the method of new energy and renewable energy to carbon emissions that are not disposed by the above methods. 


\section{(2) Model checking}

This paper compares simulation results from 2002 to 2012 with actual values of main variables in NSAS model to assess the validity of the model. The simulation value and actual value of tourists' quantity appears a rather great deviation in the middle period of observation, which is mainly caused by SARS and earthquakes. By 2011, tourists' quantity reached the number before the earthquake. Therefore, the data of 2003, 2008, 2009 and 2010 are excluded. The average relative error of tourists' quantity is $11 \%$; the average relative error of benefits from carbon emissions per unit is $6.9 \%$; the average relative error of sewage centralized disposal rate is $2 \%$; the average relative error of garbage decontamination rate is $2.6 \%$; the average relative error of resident income per capita is $10 \%$; the average relative error of research investment is $8.6 \%$; the average relative error of environmental protection investment is $8.1 \%$.

In summary, given the adverse effect of "SARS" and earthquakes being eliminated, the difference between simulation values and actual values of main variables is controlled within $11 \%$. Considering the particularity and complexity of scenic area system development, the precision of above data can satisfy the model's requirements, so the model passes the test and can be used for system regulation and analysis in Jiuzhai Valley.

\section{System regulation and analysis}

Regulation and analysis on main factors that may affect ecological civilization construction in Jiuzhai Valley are conducted to explore the trend of ecological civilization construction in natural scenic areas under different strategies, with the aim to provide decision-making ideas and plans for natural scenic area administrators. Garbage handling capacity, sewage disposal capacity, and artificial carbon emissions handling capacity play a decisive role in the construction of ecological civilization in natural scenic areas. Therefore, the weights of indexes related to five dimensions of economic operation, social development, ecological representation, decarbonated control, and constructive guarantee are calculated by gray correlation method and G1 integrated method, so as to obtain value of each dimension, and compare variation trends of each subsystem year-by-year under the unified scale.

\section{(1) Regulation on garbage handling capacity}

Assuming that other variables remain unchanged and garbage handling capacity is changed, the trends of change process of five dimensions-economic operation, social development, ecological representation, decarbonated control, and constructive guarantee are examined in comparition with changes in garbage disposal rate from 2013 to 2025 . As garbage disposal rate increases from $20 \%$ to $100 \%$, performance of economic operation dimension becomes more stable. When garbage disposal rate reaches $20 \%$, the economic growth trend declines sharply in comparison with influence from other rates; under other circumstances, trend of change process of economic operation dimension value remains basically the same; in view of social development dimension, the value is distributed from small to large, and social development slows down slowly, tending to be stable around 2025; for ecological representation dimension, its change trend is approximately the same with that of social development dimension, tending to stay stable and reaching a steady value around 2025; from the perspective of decarbonated control dimension, except when garbage disposal rate reaches $20 \%$, the dimension value changes from small to large, under other circumstances, the curve of dimension value changes from small to large, and then to small, reaching its maximum value around 2019 , and tending to be stable around 2023; from the viewpoint of constructive guarantee, the higher the garbage handling capacity is, the larger the value of constructive guarantee reaches. The change in this dimension value gradually slows down and tends to be stable. From the perspective of the entire Jiuzhai Valley NSAS (as shown in Fig. 3), longitudinally, when garbage handling capacity changes from $20 \%$ to $100 \%$, the system lumped dimension value of economic operation, social development, ecological representation, decarbonated control, and constructive guarantee gradually increases; horizontally, as time goes by, the value decreases slightly and gradually stabilizes, indicating that the decarbonated development speed of scenic areas is slightly declined promoting ecological civilization construction.

\section{(2) Regulation on sewage disposal capacity}

Assuming that other variables remain unchanged while sewage disposal capacity is changed, the trends of change process of five dimensions-economic operation, social development, ecological representation, decarbonated control, and constructive guarantee are examined in comparition with changes in sewage disposal rate from 2013 to 2025 . As sewage disposal rate increases from $20 \%$ to $100 \%$, when sewage disposal capacity takes a lower value, economic operation dimension value reaches a larger value, but as time passes by, the dimension value drops faster compared 


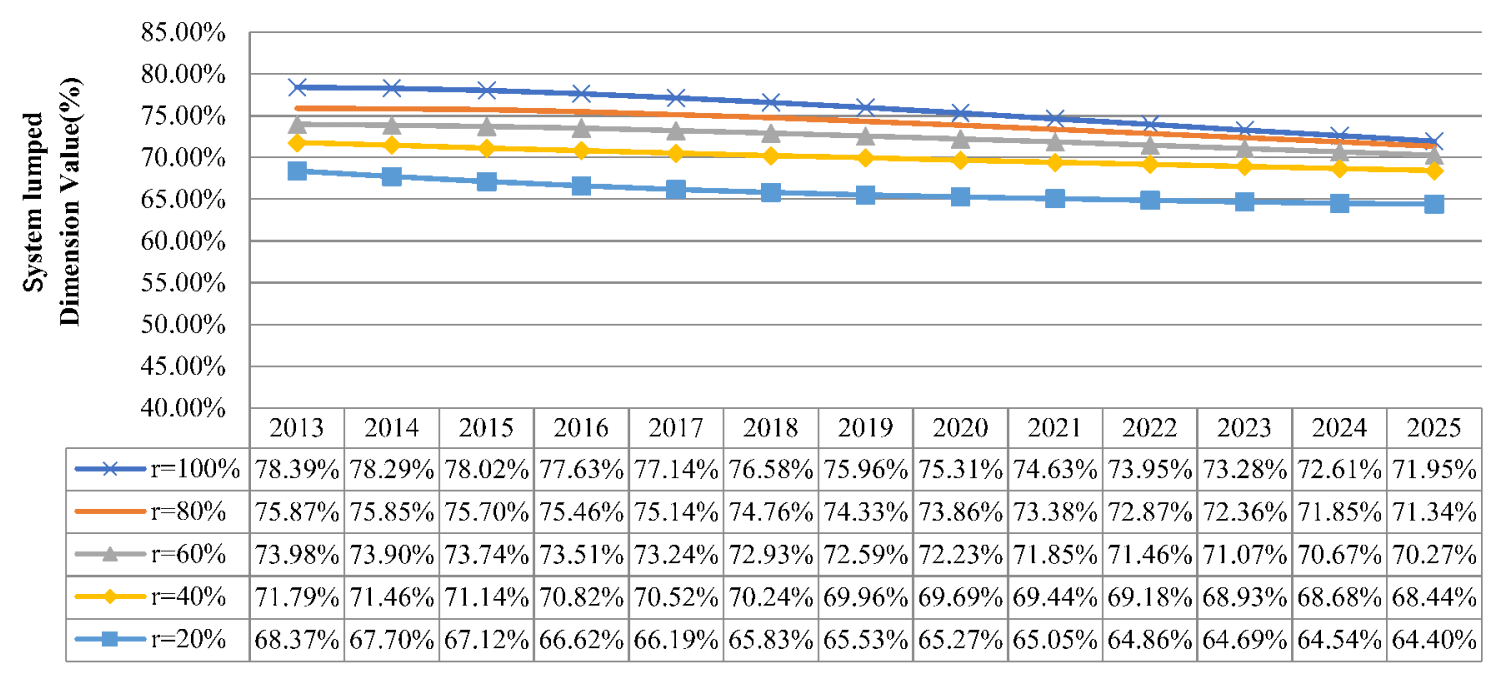

Fig. 3. Changes in impact of garbage handling capacity regulation on NSAS

with the condition when a higher value is adopted; after sewage disposal rate reaches $80 \%$, the dimension value is basically unchanged; from the perspective of social development, the dimension value shows a downward trend with a small decreasing amplitude as time goes by. As sewage disposal capacity increases, social development dimension value gradually enlarges and amplitude of variation gradually reduces; in view of ecological representation, the higher the sewage disposal rate is, the larger the dimensional value will be, and the value tends to be more stable, reaching a steady value around 2025; in the aspect of decarbonated control, when the values of sewage disposal rate differ, the dimension values are greatly different. Then, under the influence of improving sewage disposal capacity, the dimension value becomes higher and higher, and curve changes tend to be more and more stable; in view of constructive guarantee, when the dimension value keeps rising and sewage disposal rate exceeds $80 \%$, while amplitude of variation of dimension value gradually decreases. From the perspective of the entire Jiuzhai Valley NSAS (as shown in Fig. 4), on the condition that sewage disposal capacity keeps improving, the system lumped dimension value gradually increases with a small scale, indicating that the decarbonated development tends to be more and more stable.

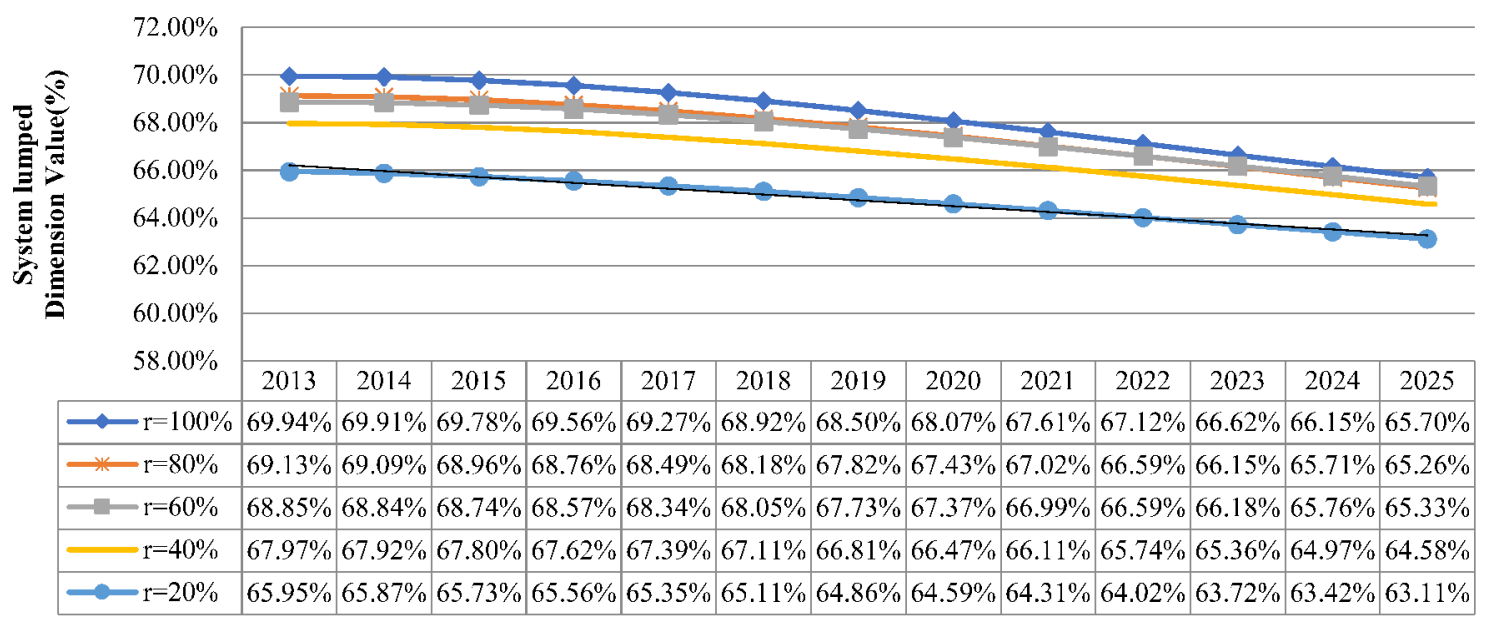

Fig. 4. Changes in impact of sewage disposal capacity regulation on NSAS 


\section{(3) Regulation on artificial carbon emissions hand- ling capacity}

Assuming that other variables remain unchanged while artificial carbon emissions handling capacity varies, the trends of change process of five dimensions-economic operation, social development, ecological representation, decarbonated control, and constructive guarantee are examined in comparision with changes in artificial carbon emissions handling rate from 2013 to 2025 . As artificial carbon emissions handling rate increases from $5 \%$ to $25 \%$, the increasing pollution handling costs slightly reduce the corresponding economic operation dimension value in 2013. Since 2015, the increase in the use of renewable energy improves artificial carbon emissions handling capacity, and its dimension value continues to rise. The effect of increasing handling rate of artificial carbon emissions on the dimension value of economic operation appears to be more and more obvious; in view of social development, there is a slight increase in the dimension value of social development with no significant impact, thus having no dominant effect on social development; from the perspective of ecological representation, the change in artificial carbon emissions capacity shows a significant impact on ecological environment. As artificial carbon emissions handling rate continuously increases, ecological representation dimension value rises steadily. However, when artificial carbon emissions handling capacity becomes higher and higher, especially after reaching $20 \%$, there's no obvious changes in the dimension value of ecological representation, indicating that when artificial carbon emissions handling rate exceeds $20 \%$, it does not play a major role in ecological representation; from the perspective of decarbonated control, before 2017, since the positive effect of increased carbon emissions handling rate on carbon emissions control cannot counteract its adverse effect on increased garbage decontamination rate and sewage centralized disposal rate, the improvement of artificial carbon emissions handling capacity does not immediately come into effect in driving decarbonated control dimension value. However, in later period, the increase trend of artificial carbon emissions disposal rate has an increasingly obvious effect on the rise of decarbonated control dimension value; in view of constructive guarantee, the dimension value changes slightly with high consistency in curve change, indicating that artificial carbon emissions disposal rate does not play a leading role in constructive guarantee. From the perspective of the entire Jiuzhai Valley NSAS (as shown in Fig. 5), the increase in artificial carbon emissions disposal rate gives a rise to the dimension value of decarbonated development. As artificial carbon emissions handling capacity keeps increasing, its leading role in decarbonated development gradually weakens. Therefore, when artificial carbon emissions disposal rate is relatively low, the decarbonated development of scenic areas can be achieved by improving artificial carbon emissions disposal rate.

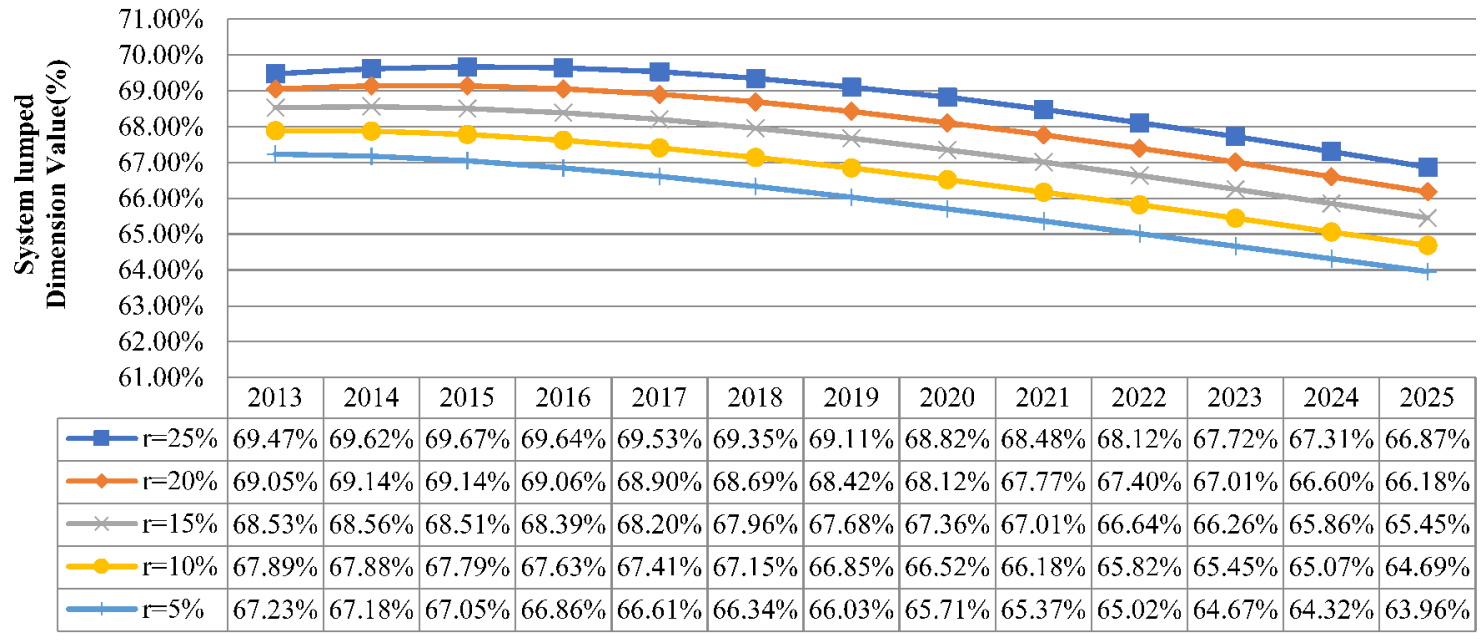

Fig. 5. Changes in impact of artificial carbon emissions handling capacity regulation on NSAS 


\section{CONCLUSIONS}

From the prospective of ecological civilization, this paper discusses the connotation of NSAS ecological civilization, uses SD method to construct NSAS model, and takes Jiuzhai Valley as research object. This paper further evaluates and analyzes Jiuzhai Valley's construction status of NSAS ecological civilization from five dimensions including economic operation, ecological representation, social development, decarbonated control, and constructive guarantee, as well as the combined process of the whole system through regulating three key factors of garbage handling capacity, sewage disposal capacity and artificial carbon emissions handling capacity. In the aim to promote the construction of NSAS ecological civilization, promote the green and decarbonated development and forge a "low-carbon scenic area", this paper gives the following suggestions based upon forecasting the regulation conditions:

(1) Consolidate ecological environmental protection and promote scientific construction of natural scenic areas

Ecological civilization construction in natural scenic areas is inseparable from the carrier of resources, a balanced eco-environment system. According to the simulation forecast, the development speed of this dimension shows a slight downward trend since 2013. To slow the trend, it is suggested to increase research investment, study on scenic area systems scientifically, formulate scientific construction plans, then constantly improve and maintain infrastructure and service facilities, so as to provide quality ecological tourism resources and constructive guarantee for ecological civilization construction in natural scenic areas.

(2) Explore innovative community management and promote harmonious coexistence between man and scenery

Judging from the forecast on the trend of social development dimension, when residents' income rises to a certain extent, the growth rate will decline. To slow the development of this dimension, in the process of further promoting ecological civilization construction, scenic areas should explore innovative community management models, reduce residents' employment cost, constantly improve residents' social security system, enrich residents' income revenues, and carry out training on low-carbon life based upon residents' understanding of ecological civilization construction, so as to help establish the awareness of low-carbon life, environmental protection and ecological civilization, and jointly promote decarbonated development in scenic areas and the harmonious coexistence between man and scenery as well.

\section{(3) Handle decarbonated control degree and pro- mote environmental protection and energy-saving technologies}

In order to continuously promote ecological civilization construction in natural scenic areas, in addition to maintaining a stable level of carbon sequestration capacity, scenic areas should formulate energy-saving and emission-reducing targets and specific implementation rules, adjust energy structure, gradually expand consumption proportion of new energy and renewable energy, so as to promote development and utilization technology of renewable clean energy; it is also suggested to advocate low-carbon tourism, organize and provide services of low-carbon tourism, encourage tourists to participate in low-carbon tourism activities, and improve artificial carbon emissions handling capacity in diversified ways.

\section{ACKNOWLEDGMENTS}

This work was supported by the National Natural Science Foundation of China (Grant Nos. 71501019, 71501138, 71601164 and 71502019), the National Social Science Foundation of China (Grant Nos. 18XJY006 and 14CJY008), the Youth Program of Social Science Research of Sichuan Province for the Twelfth Five-year Plan (Grant Nos. SC15C005 and SC15C030), China's Post-doctoral Science Fund Project (Grant No. 2018M631069), the Philosophy and Social Science Planning Program of Chengdu (Grant No. 2018A09), the General Program of the Education Department in Sichuan Province (Grant Nos. 16SB0071 and 16SB0049), the Key Program of Resource-based city Development Research Center (Grant No. ZYZX-ZD-1701), the General Program of the Sichuan Oil and Gas Development Research Center (Grant No. SKB17-01), the Funding Program for Middle-aged Core Teachers at Chengdu University of Technology (Grant No. KYGG201519), and the Special Funding for Post-doctoral Research Projects on Sichuan in 2017 Named "dynamic evolution of multi-system coupling in resource-oriented cities of western China from a technology innovation-driven perspective". 


\section{REFERENCES}

Chai Q., Guo Y., Gong C. and Li. (2017). Comprehensive Evaluation of Chinese Provincial Ecological Civilization Coordinated Development Degree. Chinese Journal of Management Science. (7), 184-190.

Chen R., Hua M. and Zhang G. (2017). Public Participation of Ecological Civilization Construction in China. Jiangxi Social Sciences. (3), 63-72.

De Leon R.C. and Kim S.M. (2017). Stakeholder perceptions and governance challenges in urban protected area management: The case of the Las Piñas- Parañaque Critical Habitat and Ecotourism Area, Philippines. Land Use Policy, 63, 470-480.

Guo X., Ming Q., Mu X. and Mu J. (2017). Study on Spatial and Temporal Evolution of Urban Tourism and Ecological Civilization: Taking Henan Province as an Example. Resource Development and Market. 33 (6), 732-737.

Kamali F.P., Meuwissen M.P.M., Boer I.J.M., van Middelaar C.E., Moreira A. and Lansink A.G.J.M.O. (2017). Evaluation of the environmental, economic, and social performance of soybean farming systems in southern Brazil. Journal of Cleaner Production. 142, 385-394.

Liu K., Li Y., Wang P. and Li H. (2013). Research on the Construction of Domestic Ecological Civilization Cities. Advanced Materials Research. 737 (734-737), 1967-1970.

Luo Y., Jin M., Ren P., Liao Z. and Zhu Z. (2014). Simulation and Prediction of Decarbonated Development in Tourist Attractions Associated with Low-carbon Economy. Sustainability. 6 (4), 2320-2337.

Mao F. (2016). Path and Countermeasures of Transformation and Upgrading of Rural Tourism from the Perspective of Ecological Civilization. Agricultural Economy, (4), 30-32.

Qin S. and Ju C. (2017). Periodic Analysis of the Evolution of the Ecological Civilization Concept: A Historical Survey Based on Global Perspective. Journal of China University of Geosciences (Social Sciences Edition). 17 (1), 19-28.
Tang C, Zhou Y., Zhong L. and He Y. (2017). Building Rural Eco-Tourism Pattern from the Ecological Civilization Construction Perspective. Ecological Economy. 33 (4), 127-132.

Villanueva-Álvaro J.J., Mondéjar-Jiménez J. and SáezMartínez F.J. (2017). Rural Tourism: Development, Management and Sustainability in Rural Establishments. Sustainability. 9 (5), 818.

Wang Y. (2017). Measurement and Comparison of Ecological Civilization Construction in China. Statistics and Decision. (3), 70-73.

Wu Z., Zhao M., Tian Z. and Ma C. (2017). Regional Comparison of Water Footprint in China Based on the Multi-Regional Input-output Analysis: In the Analytical Framework of "Amount-Relative Index-Structure". Journal of Natural Resources. 32 (1), 76-87.

Xu L., Cao S. and Liu D. (2017). Discussion on the Integration Development of Rural Tourism Development and Ecological Civilization Construction. Geography and Geo-Information Science. 6, 106-111.

Yang F. (2016). Study on Establishing Linkage System of Green Technology Innovation. Academic Forum, 38 (1), 25-30.

Yu G., Liu D., Liao X., Wang T., Tian Q. and Liao Y. (2017). Quantitative Research on Regional Ecological Compensation from the Perspective of Carbon-Neutral: The Case of Hunan Province, China. Sustainability. 9 (7), 10-95.

Zhang X., Wang Y., Qi Y., Wu J., Liao W., Shui W., Zhang Y., Deng S., Peng H., Yu X. and Qi H. (2016). Evaluating the Trends of China's Ecological Civilization Construction Using a Novel Indicator System. Journal of Cleaner Production. 133, 910-923.

Zhao J. and Li S.M. (2018). The Impact of Tourism Development on the Environment in China. Acta Scientifica Malaysia. 2(1), 1-4.

Zhu T. and Gao S. (2014). Promoting Circular Development and Recycling Solid Waste: In the View of Ecological Civilization Construction. Advanced Materials Research. 878, 873-878. 